\title{
Simulation based Performance Analysis of an End-of-Aisle Automated Storage and Retrieval System
}

\author{
Behnam Bahrami, El-Houssaine Aghezzaf and Veronique Limère \\ Department of Industrial Management, Ghent University, Technologiepark 903, Gent-Zwijnaarde, Belgium \\ \{Behnam.Bahrami, ElHoussaine.Aghezzaf,Veronique.Limere\}@UGent.be
}

\begin{abstract}
Keywords: $\quad$ Automated Storage and Retrieval Systems, End-of-Aisle, Simulation.
Abstract: This paper presents and discusses simulation of an End-of-Aisle automated storage and retrieval system, using FLEXSIM 6. The objective of the simulation model is to analyze and compare results of different control policies and physical designs. The performance measures considered for the evaluation of each control policy and layout combination are the total travel time of the crane and the number of storage and retrieval operations performed. The experiments set up and the corresponding results are discussed.
\end{abstract}

\section{INTRODUCTION}

Automated storage and retrieval systems (AS/RS) are widely used in manufacturing facilities, distribution centers and warehouses. An AS/RS system is defined as a storage system that uses fixed- path storage and retrieval machines (cranes), running on one or more rails between fixed arrays of storage racks.(Automated Storage Retrieval Systems Production Section of the Material Handling Industry of America, 2005). In such systems, stock keeping units (SKUs) arrive at an Input station from which they are moved by a crane to their storage location. In case of retrieval, the crane transports the SKUs from their storage location to an Output station. AS/RS have both some advantages and disadvantages. The effective use of an AS/RS may lead to substantial savings for a company by reducing direct and indirect labor, energy, maintenance, and building costs (Sarker et.al., 1995). Apparent disadvantages are high investments costs (approximately $\$ 634,000$ for a single aisle AS/RS), less flexibility and higher investments in control systems (about $\$ 103,000$ ), (Zollinger, 1999).

In designing an AS/RS, both physical design and control policies must be carefully considered to fully take advantages of its positive impact. On the one hand, the physical design consists of two aspects. First, the AS/RS type has to be chosen; this is what is called the system choice. Secondly, the chosen system must be configured, for example, by deciding on the number of aisles and rack dimensions; this is called the system configuration. On the other hand, the control policies are methods which determine the actions performed by the AS/RS (e.g., storage assignment, dwell point policy), (Roodbergen, 2009). An AS/RS is usually hired for transporting unit loads (e.g., fully loaded pallets) within the system; but, in many cases, only part of the unit-load may be needed to fulfill a customer's order. A common option to resolve this situation is when the AS/RS drops off the retrieved unit loads at a workstation at the end of the aisle. An operator at this workstation takes the required amount of products from the unit- load, and the AS/RS moves the remainder of the load back into the storage rack (Figure 1). This system is often referred to as an End-of-Aisle (EOA) system. If the unit-loads are bins, then the system is generally called a miniload AS/RS (Roodbergen, 2009). In this study various design scenarios for End-of-Aisle automated storage/retrieval systems are evaluated via simulation.

\section{LITERATURE REVIEW}

Hausman et al., (1976) initiated evaluation of performance in AS/RS systems using analytical and empirical methods. Specifically, they addressed the problem of optimal storage assignment with considering two main policies: randomized storage and class-based storage. 


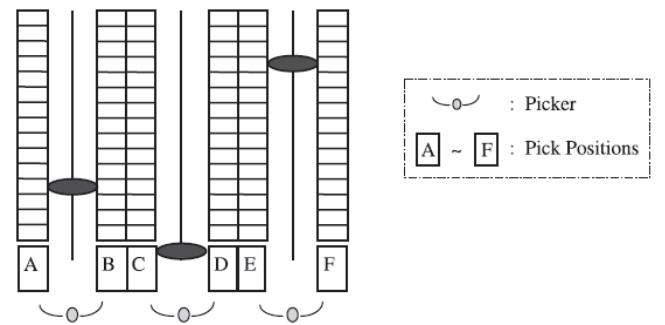

Figure 1: End-of-Aisle AS/RS order picking system (Hwang et al., 2002).

They showed that significant reductions in $\mathrm{S} / \mathrm{R}$ machine travel time are achieved from turnoverbased storage rules such as a class-based storage policy. Accordingly, Bozer and White (1984) developed a continues rack configuration to evaluate single and dual travel times for rectangular racks and variety of $\mathrm{I} / \mathrm{O}$ configurations. Furthermore, Han et al., (1987) illustrated that by sequencing the retrieval orders, the throughput performance of the AS/RS can be improved. This can thus reduce the interleaving travel time between storage and retrieval locations in a dual command cycle.

For simulation models in AS/RS, most of the researchers only evaluated some of the physical design aspects in combination with a limited number of control policies. Meller and Mungwattana (2005) applied simulation to evaluate the benefits of different dwell point policies. The results indicate that the position of dwell point has an negligible effect on system respond time when the AS/RS has high utilization. Randhawa and Shroff (1995) examined the effect of different sequencing rules on six layout configurations (with varying I/O-point, item distribution over racks, rack configuration and rack dimensions). Based on a limited number of experiments they mentioned in their study that the position of I/O point at the middle of the rack results in a higher throughput. Vanderberg et al., (2000) have developed a simulation study and examined various aspects of AS/RS control policies: storage location assignment policies, request selection rules, open location selection rules and urgency rules. Considering randomized storage and class-based storage, they concluded that using a FCFS sequence for the retrievals by implementing urgency rules result in better expected time. Randhawa et al., (1991) used simulation to evaluate single and dual I/O point configurations in a unit load AS/RS and their model demonstrated that the dual dock layout maximizes the throughput.

In an End-of-Aisle AS/RS, current retrieval operation become next storage operation, since loads are returned into the system after items have been picked. A mathematical model to investigate the performance of an EOA order picking systems have been proposed by Bozer and White (1996). They provided some approximate expressions for the expected travel time for systems performing under peak demand, and presented a design algorithm in order to calculate the minimum number of miniload aisles needed to meet a given throughput requirement. Foley and Frazelle (1991) have developed an exact solution for the $\mathrm{S} / \mathrm{R}$ machine travel time under the FCFS retrieval policy in order to evaluate the throughput for the miniload AS/RS. Hwang et al., (2002) proposed the design of miniload AS/RSs in combination with Automated Guided Vehicles. To recognize the optimal number of loads transferred by each AGV to machines, a non-linear model and heuristics have been developed in their research.

To the best of our knowledge, there is no simulation model for the End-of-Aisle system, therefore in this study a multitude of physical design aspects and control policies are simultaneously included for the End-of-Aisle system.

\section{SIMULATION MODELING OF THE SYSTEM}

\subsection{Assumptions}

In the system analyzed, a crane serves a single aisle with storage racks placed on one side of the aisle. All storage locations are identical in size and each location can hold one unit load. The total capacity of the system is 100 unit loads. Each unit load (e.g., pallet) contains a number of boxes of one item type. Although the pallet sizes are constant, the size of the boxes on the pallets are different for different item types. The crane's pick-up and deposit time is calculated according to the size and number of boxes inside the pallet; for pallets with a higher number of boxes and larger boxes, the time for pick- up and deposit is higher. Moreover, the times for manual loading and unloading boxes from pallets are calculated according to the boxes' dimension.

The turnover of each itemtype is known in advance and is the same for all scenarios tested. The crane scheduling rule in this study is FCFS (first come, first serve) for both storage and retrieval operations. The capacity of the crane is 
one pallet and the crane can move horizontally and vertically simultaneously. Crane acceleration and deceleration are assumed instantaneous. The actual travel time equals the maximum of the horizontal and vertical travel time (Chebyshev distance metric).

A unit-load AS/RS can perform in two ways, namely in a single command cycle or in a dual command cycle. In a single command cycle the crane operates either a single storage or a single retrieval operation. The storage cycle time then is equal to the sum of the time to pick-up a load at the input station, the time to travel to the storage location, the time to place the load in the rack and the time to return to the input station. The retrieval cycle time can be defined similarly. A dual command cycle can be defined as performing both a storage and a retrieval request simultaneously in a single cycle. In this case, the cycle time is defined as the sum of the time to pick up the load, the time to travel to the storage location and store the load, the empty travel time (interleaving time) from the storage location to the retrieval location and the time to pick the unit-load and transport it to the output station. In this study the crane can perform both single and dual command. This means when both storage and retrieval orders are in the queue, the crane performs in dual command but when only a storage order or a retrieval order is available, the crane moves in single command.

If the pallets' arrival rate is very high, the system will be completely operating on dual command, while by reducing the arrival rate, single- and dual- command cycles will be combined in the system. To provide a better basis for analyzing the system, in this study five scenarios for arrival of pallets to the system are assumed. Arrival rates are $25,40,60,80$ and 100 per hour respectively.

To study the End-of-Aisle system described, we simulated storage and retrieval for a number of different scenarios. In the following sections, we give an overview of the factors included.

\subsection{Configurations of Rack}

Since cranes can move vertically and horizontally simultaneously, a good balance between rack height and length can help to reduce travel times. In this study three configurations are assumed. The first configuration consists of 10 bays, and 10 levels; the second has 5 bays and 20 levels; and the third one has 20 bays and 5 levels (Figures 2, 3, 4).

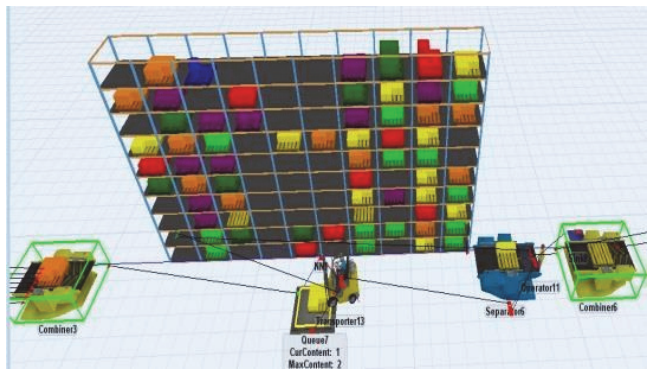

Figure 2: Rack with 10 bays and 10 levels.

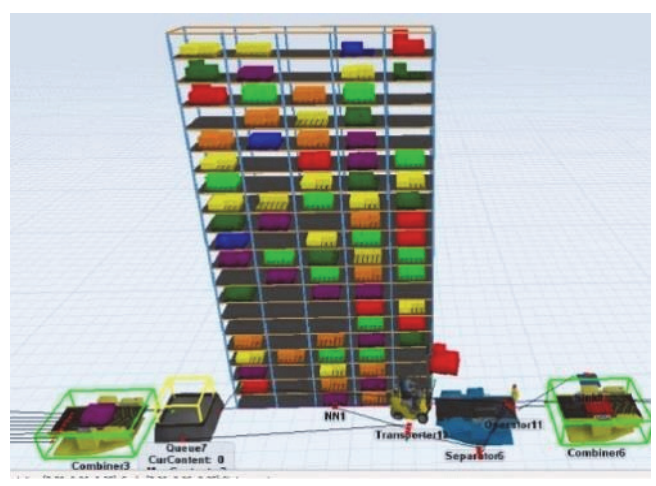

Figure 3: Rack with 5 bays and 20 levels.

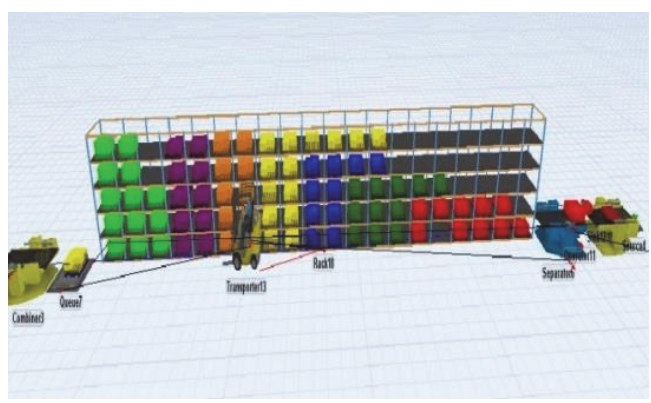

Figure 4: Rack with 20 bays and 5 levels.

\subsection{Input/Output Station}

An input station is the location where incoming products are received from other parts of the warehouse by for example, automated guided vehicles, conveyors, or forklift trucks, before they are stored. An output station is where retrieved products are unloaded before being moved to shipping. In this End-of-Aisle model, it is assumed the output station is at the end of the aisle. For the input station however, two different positions are assumed, one in the first bay of the rack and a second one in the middle of the rack (Figure 5). 


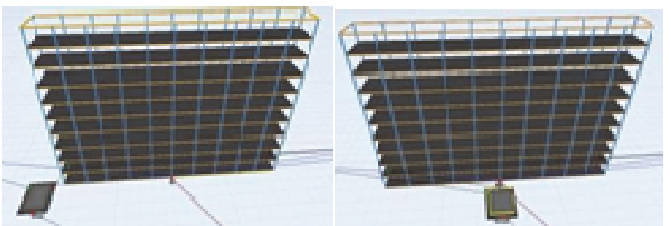

Figure 5: Location of input station: in the first bay (a), in the middle of the rack (b).

\subsection{Storage Assignment Policies}

In this model two storage policies are considered, i.e. random storage and class-based storage. For random storage, every incoming pallet is assigned to a location in the racks that is selected randomly from all eligible empty locations with equal probability (Figure 6). For class-based storage the racks and pallets are divided into $\mathrm{K}$ classes based on their turnover frequency. Pallets with higher demand frequency are assigned to class I while pallets with smaller demand frequency are assigned to class II and so on. The position of class I is the best location close to the Output station. For class II the position is the second best location near the Output station (Figure 7).

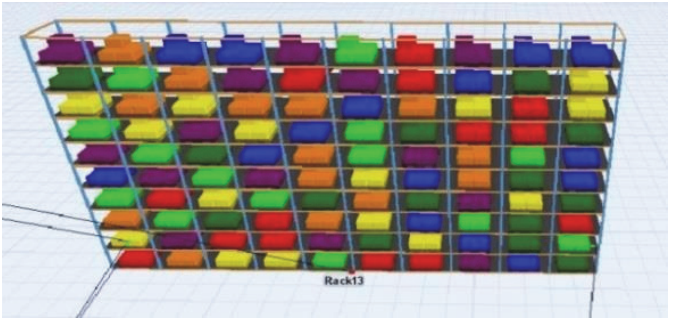

Figure 6: Random-based storage.

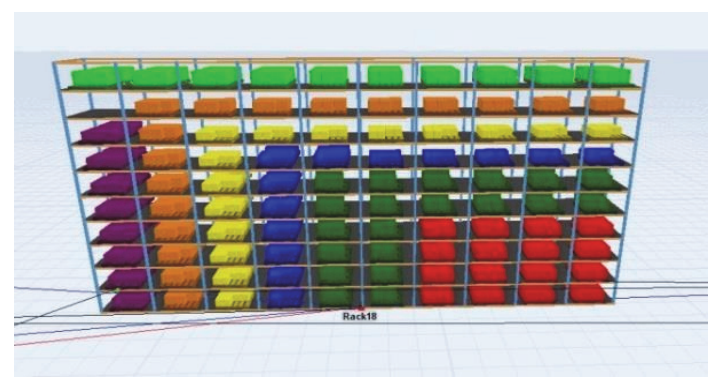

Figure 7: Class-based storage.

\subsection{Dwell Point Policy}

When the crane is idle, its location is called as the dwell point. Choosing a proper dwell point can minimize the expected travel time for the next operation. In this model three dwell points are considered: at the Input station, in the middle of the aisle and at the Output station respectively (Figure 8).

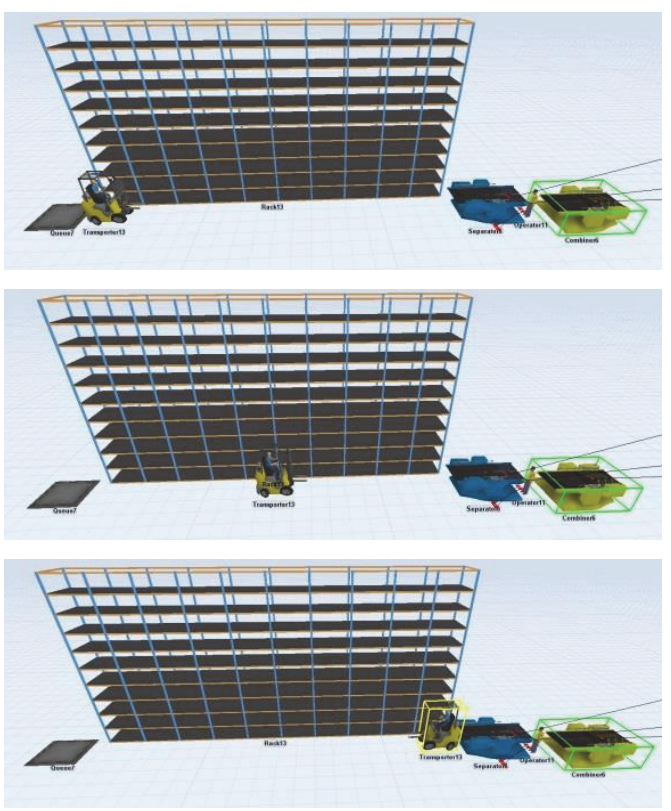

Figure 8: Position of crane: in the Input station (a), in the middle of the rack (b), in the Output station (c).

\section{SIMULATION RESULTS}

The simulation results are given in the following tables. For each storage policy - i.e. random storage and class-based storage different physical designs are analyzed for five arrival rates of pallets. Specifically, for each case the performance of the system is evaluated according to dwell point, input station and rack configuration. Each simulation is run for 3600 seconds. The measures of performance are: total travel time of the crane and total number of storages and retrievals performed by the system.

To evaluate the performance of the model, the simulation was initiated with storage rack utilization at zero (rack is completely free). Considering the nature of random storage, the simulation results are based on 40 replications for each scenario, and the average results are reported. Results of the experiments can be read from Table 1 and 2 .

In the following subsections we will discuss the results.

\subsection{Total Travel Time of the Crane}

The following plot indicates that the total travel time increases significantly when the number of 
Table 1: Total crane's travel and total number of storage and retrievals for Random Based Storage.

\begin{tabular}{|c|c|c|c|c|c|c|c|c|c|c|c|c|}
\hline \multirow{3}{*}{$\begin{array}{l}\text { Dwell } \\
\text { Point }\end{array}$} & \multirow{3}{*}{$\begin{array}{l}\text { Input } \\
\text { station }\end{array}$} & \multirow{3}{*}{$\begin{array}{l}\text { Rack } \\
\text { B*L }\end{array}$} & \multicolumn{10}{|c|}{ Arrival rate (pallets/h) } \\
\hline & & & \multicolumn{2}{|c|}{25} & \multicolumn{2}{|c|}{40} & \multicolumn{2}{|c|}{60} & \multicolumn{2}{|c|}{80} & \multicolumn{2}{|c|}{100} \\
\hline & & & TT & $\mathrm{S} / \mathrm{R}$ & TT & $\mathrm{S} / \mathrm{R}$ & TT & $\mathrm{S} / \mathrm{R}$ & $\mathrm{TT}$ & $\mathrm{S} / \mathrm{R}$ & TT & $\mathrm{S} / \mathrm{R}$ \\
\hline Input & first & $20 * 5$ & 1758 & 35 & 3017 & 57 & 4326.4 & 77 & 4571.5 & 78 & 4603.9 & 82 \\
\hline Input & middle & $20 * 5$ & 1155 & 36 & 2013 & 58 & 3043.2 & 84 & 3563.8 & 103 & 3733.5 & 110 \\
\hline Output & first & $20 * 5$ & 1798 & 35 & 3075 & 57 & 4366.2 & 77 & 4619.2 & 78 & 4679.6 & 82 \\
\hline Output & middle & $20 * 5$ & 1154 & 36 & 2025 & 58 & 3042.3 & 84 & 3554.7 & 103 & 3732.6 & 110 \\
\hline Middle & first & $20 * 5$ & 1778 & 35 & 3037 & 57 & 4346.2 & 77 & 4591 & 78 & 4627.8 & 82 \\
\hline Middle & middle & $20 * 5$ & 1136 & 36 & 1994 & 58 & 3023.9 & 84 & 3534.3 & 103 & 3710.3 & 110 \\
\hline Input & first & $10 * 10$ & 866 & 36 & 1496 & 58 & 2248.5 & 84 & 2963.4 & 108 & 3245.7 & 122 \\
\hline Input & middle & $10 * 10$ & 526 & 36 & 970 & 59 & 1380.7 & 83 & 1779.5 & 109 & 2049.3 & 131 \\
\hline Output & first & $10 * 10$ & 885 & 36 & 1516 & 58 & 2148.3 & 84 & 2822.6 & 108 & 3265.9 & 122 \\
\hline Output & middle & $10 * 10$ & 525 & 36 & 969 & 59 & 1379.6 & 83 & 1778.3 & 109 & 2047.5 & 131 \\
\hline Middle & first & $10 * 10$ & 875 & 36 & 1506 & 58 & 2258.2 & 84 & 2973.3 & 108 & 3255.9 & 122 \\
\hline Middle & middle & $10 * 10$ & 517 & 36 & 961 & 59 & 1371.4 & 83 & 1770.1 & 109 & 2037.3 & 131 \\
\hline Input & first & $5 * 20$ & 415 & 36 & 735 & 60 & 1094.6 & 83 & 1440.5 & 109 & 1685.6 & 131 \\
\hline Input & middle & $5 * 20$ & 223 & 36 & 441 & 60 & 583.96 & 84 & 739.89 & 109 & 863.22 & 132 \\
\hline Output & first & $5 * 20$ & 425 & 36 & 745 & 60 & 1104.4 & 83 & 1450.3 & 109 & 1696.4 & 131 \\
\hline Output & middle & $5 * 20$ & 222 & 36 & 420 & 60 & 579.46 & 84 & 738.34 & 109 & 861.62 & 132 \\
\hline Middle & first & $5 * 20$ & 420 & 36 & 740 & 60 & 1099.5 & 83 & 1445.4 & 109 & 1689.8 & 131 \\
\hline Middle & middle & $5 * 20$ & 219 & 36 & 417 & 60 & 579.46 & 84 & 735.39 & 109 & 858.58 & 132 \\
\hline
\end{tabular}

Table 2: Total cranes travel time and total number of storages and retrievals for Class-Based storage.

\begin{tabular}{|c|c|c|c|c|c|c|c|c|c|c|c|c|}
\hline \multirow{3}{*}{$\begin{array}{l}\text { Dwell } \\
\text { Point }\end{array}$} & \multirow{3}{*}{$\begin{array}{l}\text { Input } \\
\text { station }\end{array}$} & \multirow{3}{*}{$\begin{array}{l}\text { Rack } \\
\mathrm{B}^{*} \mathrm{~L}\end{array}$} & \multicolumn{10}{|c|}{ Arrival rate (pallets/h) } \\
\hline & & & \multicolumn{2}{|c|}{25} & \multicolumn{2}{|c|}{40} & \multicolumn{2}{|c|}{60} & \multicolumn{2}{|c|}{80} & \multicolumn{2}{|c|}{100} \\
\hline & & & TT & $\mathrm{S} / \mathrm{R}$ & TT & $\mathrm{S} / \mathrm{R}$ & TT & $\mathrm{S} / \mathrm{R}$ & TT & $\mathrm{S} / \mathrm{R}$ & TT & $\mathrm{S} / \mathrm{R}$ \\
\hline Input & first & $20 * 5$ & 1568 & 35 & 2583 & 56 & 4044.3 & 81 & 4561.7 & 100 & 4888.1 & 118 \\
\hline Input & middle & $20 * 5$ & 1091 & 36 & 1923 & 58 & 2830.4 & 83 & 3259.6 & 104 & 3608.5 & 124 \\
\hline Output & first & $20 * 5$ & 1564 & 35 & 2622 & 56 & 4084 & 81 & 4586.4 & 100 & 4947.9 & 118 \\
\hline Output & middle & $20 * 5$ & 1087 & 36 & 1906 & 58 & 2820.3 & 83 & 3287.1 & 104 & 3604.6 & 124 \\
\hline Middle & first & $20 * 5$ & 1587 & 35 & 2570 & 56 & 4064 & 81 & 4553.6 & 100 & 4907.9 & 118 \\
\hline Middle & middle & $20 * 5$ & 1078 & 36 & 1903 & 58 & 2810.4 & 83 & 3270.8 & 104 & 3585.5 & 124 \\
\hline Input & first & $10 * 10$ & 758 & 36 & 1311 & 59 & 1992.8 & 84 & 2616.2 & 107 & 2944.2 & 128 \\
\hline Input & middle & $10 * 10$ & 574 & 36 & 991 & 59 & 1402 & 84 & 1834.5 & 109 & 2083.7 & 130 \\
\hline Output & first & $10 * 10$ & 735 & 36 & 1331 & 59 & 2012.5 & 84 & 2636 & 107 & 2968.3 & 128 \\
\hline Output & middle & $10 * 10$ & 570 & 36 & 987 & 59 & 1398.3 & 84 & 1830.3 & 109 & 2079.6 & 130 \\
\hline Middle & first & $10 * 10$ & 757 & 36 & 1252 & 59 & 2002.5 & 84 & 2626 & 107 & 2958.1 & 128 \\
\hline Middle & middle & $10 * 10$ & 564 & 36 & 981 & 59 & 1392.5 & 84 & 1824.4 & 109 & 2073.1 & 130 \\
\hline Input & first & $5 * 20$ & 351 & 36 & 623 & 59 & 943.71 & 84 & 1348.8 & 109 & 1509.1 & 132 \\
\hline Input & middle & $5 * 20$ & 255 & 36 & 442 & 60 & 589.27 & 84 & 756.28 & 109 & 849.68 & 133 \\
\hline Output & first & $5 * 20$ & 328 & 36 & 633 & 59 & 953.48 & 84 & 1358.6 & 109 & 1518.8 & 132 \\
\hline Output & middle & $5 * 20$ & 251 & 36 & 438 & 60 & 585.22 & 84 & 759.94 & 109 & 845.64 & 133 \\
\hline Middle & first & $5 * 20$ & 356 & 36 & 628 & 59 & 948.50 & 84 & 1353.6 & 109 & 1513.9 & 132 \\
\hline Middle & middle & $5 * 20$ & 250 & 36 & 437 & 60 & 584.16 & 84 & 758.88 & 109 & 844.58 & 133 \\
\hline
\end{tabular}


arriving pallets to the system change from 25 to 60 , but for higher rates of incoming pallets from 60 to 100 , the total crane's travel time rises slowly and become more stable.

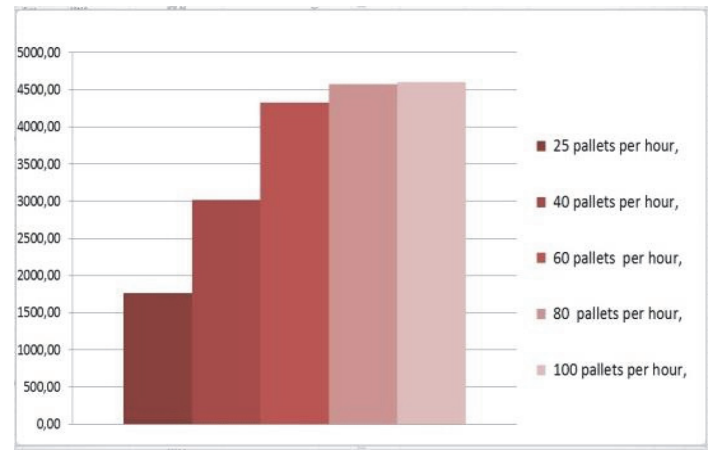

Figure 9: Total crane's travel times for different arrival rates.

\subsection{Random based Storage Vs. Class-based Storage}

Based upon the crane's travel time and the number of storages and retrievals carried out by the system, the analysis demonstrates that class- based storage offers a better performance than random based storage. The comparison between both types is given in Figure 11 and Figure 12.

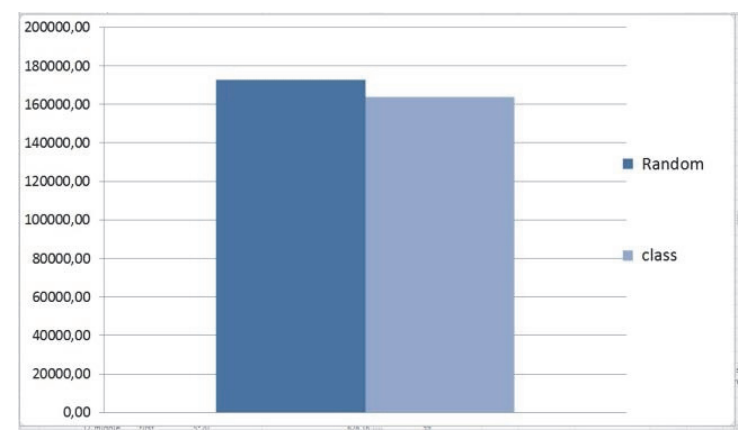

Figure 10: Total travel times for random and class-based.

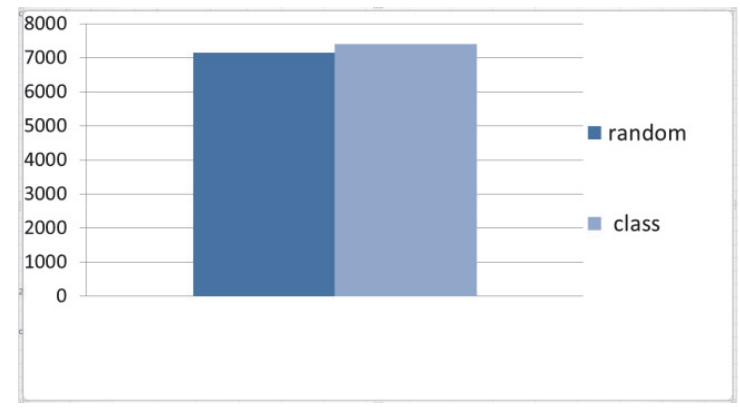

Figure 11: Number of storages and retrievals for random and class-based.

\subsection{Rack Configuration}

The result obtained for different configurations indicate that with increasing in the number of bays, the total travel time increases and the total number of storages and retrievals increase. figures $(13,14)$.

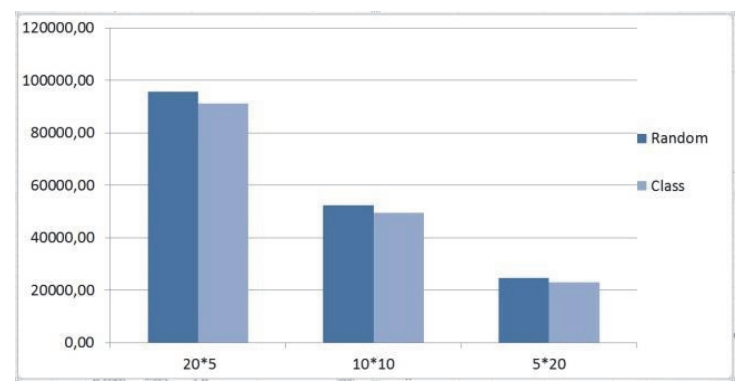

Figure 12: Total crane's travel time.

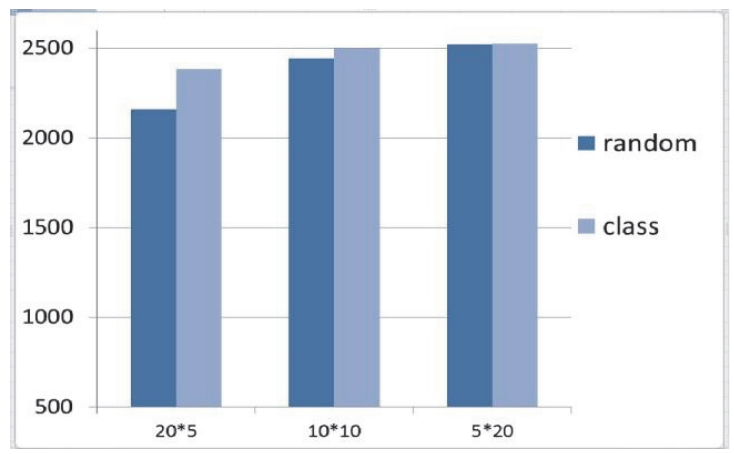

Figure 13: Total number of storages and retrievals.

\subsection{Input Station Location}

According to the results it can be observed that the best location for dock, is at the middle of the rack. The given diagrams illustrate the total travel distance and total number of retrievals and storages

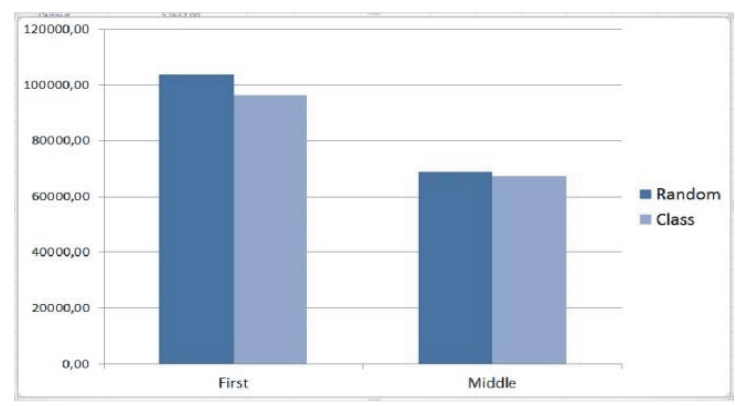

Figure 14: Total crane's travel time. 


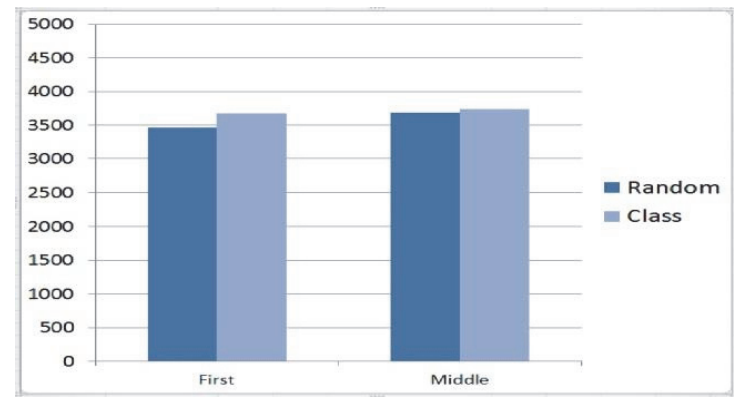

Figure 15: Total number of storages and retrievals.

\subsection{Dwell Point Location}

The results achieved by the simulation model, reveal that the position of dwell point has negligible impact on both travel time and number of storage and retrievals. The following figures represent the comparison for three dwell point locations.

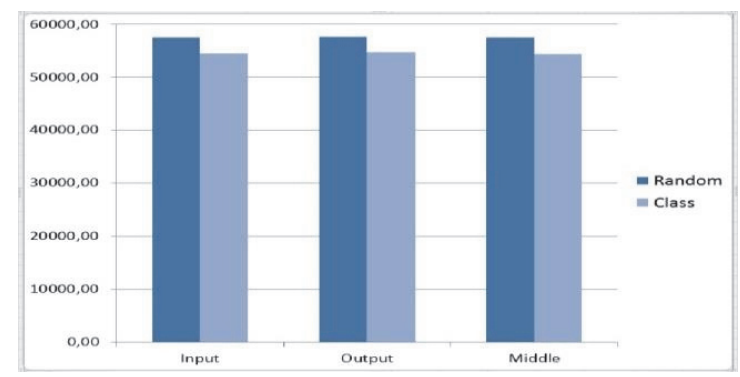

Figure 16: Total crane's travel time.

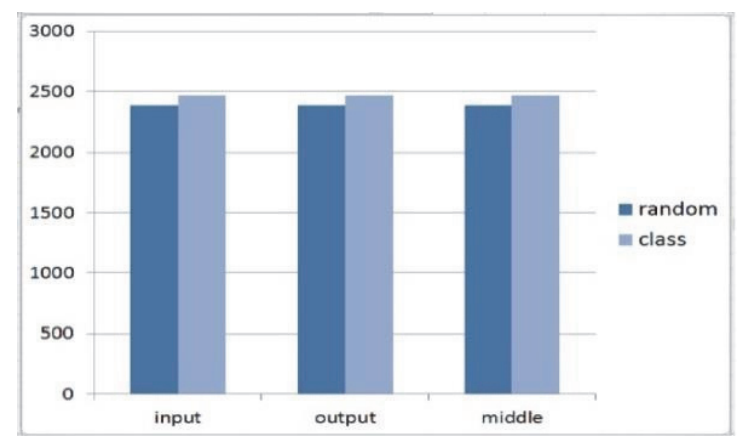

Figure 17: Total number of storages and retrievals.

\section{CONCLUSIONS}

This paper presents a simulation based performance analysis of an End-of-Aisle automated storage and retrieval system. Results of different control policies and physical designs were compared. In particular, the efficiency of the system for two types of storage, namely class-based and random based, with combinations of different dwell points, Input locations and various rack configurations, were analyzed. This preliminary analysis shows that combination of class-based storage with an input station in the middle of the rack, seems to provide a superior performance. The analysis with other strategies is ongoing.

\section{REFERENCES}

Automated Storage Retrieval Systems Production Section of the Material Handling Industry of America (2005).

Sarker, B. R., Sobhan B., 1995. "Travel time models in automated storage/retrieval systems: A critical review". Int. Journal of Production Economics 40173, 184-193.

Bozer, Y. A., and White, J. A., 1984, "Travel time models for automated storage/retrieval systems". IIE Transactions, 16 (4), 329- 338.

Bozer, Y. A., White, J. A., 1996. "A generalized design and performance analysis model for end-of-aisle order- picking systems". IIE Transactions 28 (4), 271 280.

Foley, R. D., Frazelle, E. H., 1991. "Analytical results for miniload throughput and the distribution of dual command travel time". IIE Transactions 23 (3), 273281.

Graves, S. C., Hausman, W. H., Schwarz, L. B., 1977. "Storage-retrieval interleaving in automatic warehousing systems". Management Science 23 (9), 935-945.

Han, M. H., McGinnis, L. F., Shieh, J. S., White, J. A., 1987. "On sequencing retrievals in an automated storage/retrieval system". IIE Transactions 19 (1), 56 66.

Hausman, W. H., Schwarz, L. B., Graves, S. C., 1976. "Optimal storage assignment in automatic warehousing systems". Management Science 22 (6), 629-638.

Hwang, H., Moon, S., Gen, M., 2002. “An integrated model for the design of end-of-aisle order picking system and the determination of unit load sizes of AGVs". Computers \& Industrial Engineering 42, 249-258.

Kees Jan Roodbergen , Iris F. A. Vis., 2009. “A survey of literature on automated storage and retrieval systems". European Journal of Operational Research 194, 343362.

Meller, R. D, Mungwattana. A., 2005. "AS/RS dwell point strategy selection at high system utilization: A simulation study to investigate the magnitude of the benefit". International Journal of Production Research 43(24), 5217-5227.

Randhawa, S. U., McDowell, E. D., Wang, T. W., 1991. "Evaluation of scheduling rules for single- and dualdock automated storage/retrieval system". Computers \& Industrial Engineering, Volume 20, Issue 4, 401410 . 
Randhawa, S. U., Shroff, R., 1995. "Simulation-based design evaluation of unit load automated storage/retrieval systems". Computers \& Industrial Engineering 28 (1), 71-79.

Van den Berg, J. P., Gademann, A. J. R. M., 2000. "Simulation study of an automated storage/retrieval system". International Journal of Production Research 38 (6), 1339-1356. 